\title{
CuANdo las Normas Penales en Blanco VulNeran El PRINCIPIO DE LEGALIDAD
}

SANDRA EUGENIA ZÚÑIGA MoRALES

Doctora en Derecho Penal

Universidad de Alcalá

\section{Introducción}

$\mathrm{E}$

1 Derecho penal recurre a la técnica de la norma penal en blanco y otras, motivado por la cambiante realidad científica y social. A cada instante surgen cantidad de variantes (nuevos conocimientos y materiales, así como otros usos y necesidades), que llevan a una rápida evolución tecnológica y a una acentuada inestabilidad de patrones fijos. Ello conduce a tener que valorar circunstancias mutantes -que atentan o lesionan bienes jurídicos- difíciles de encasillar en un precepto penal, motivo por el que surgen otras opciones más dinámicas como resultan ser las normas penales en blanco ${ }^{1,2}$ Éstas tienen la ventaja de excepcionar el paso por extenuantes procesos legislativos, que por lo general caracterizan todas las iniciativas de reforma legal. ${ }^{3}$

Sin embargo, los peligros que entrañan no resultan despreciables, por la posibilidad de vulnerar principios esenciales de un sistema de Derecho democrático: principio de legalidad, de seguridad, de separación de poderes ${ }^{4}$ y entre otros, el principio de tipicidad penal recogido en el ordenamiento constitucional costarri-

${ }^{1}$ DOVAL PAIS, Norma penal, 1999, p.108, al analizar la necesidad de utilizar las normas penales en blanco en determinadas materias, opina: "Son, pues, bienes jurídicos altamente formalizados, cuya indemnidad se hace depender del mantenimiento de una serie de condiciones establecidas en términos de 'no transgresión' de otras normas (aunque no toda vulneración de estas condiciones dé lugar, automáticamente, a una afección con relevancia penal). Los bienes jurídicos de estas características son de naturaleza supraindividual o colectiva; en particular son, además, difusos y carecen, por lo general, de referente individual. Algunos ejemplos de ellos serían el orden socioeconómico, la ordenación del territorio, el medio ambiente y los recursos naturales."

${ }^{2}$ Así lo ha entendido también nuestra Sala Constitucional que en el voto No.2757-93 de las 14:45 hrs. del 15 de junio de 1993, señala: "Es frecuente que dada la especialidad de la materia y la rapidez con que pueden variar las circunstancias -la materia económica y comercial es una de ellas- el legislador se vea obligado a recurrir a la técnica, en todo caso excepcional, de las denominadas leyes penales en blanco."

3 Agrega DOVAL PAIS, Norma penal, 1999, p.109.

${ }^{4}$ Cfr. MORILLAS CUEVA/ RUIZ ANTÓN, MDP, 1992, p.66; BLANCO LOZANO, LL, 1997- 4, p. 711; Delito ecológico, 1997, p.37. 
cense en el art. $39^{5}$, por el cual toda causa penal se origina sobre la base de una definición legal previa. ${ }^{6}$

Nuestra legislación no ha resultado ajena al uso de esta técnica legislativa, como lo ilustran diversas disposiciones. El interés por este tema surge al revisar el criterio jurisprudencial existente en nuestro país y la necesidad de reforzar los aspectos que deben representar garantía de legalidad a su admisibilidad, para tener una visión clara ahora y a futuro de lo que debe o no tolerarse bajo la etiqueta de una "norma penal en blanco".

Esta ponencia consta de dos partes. La primera fija aspectos conceptuales; la segunda se dedica en exclusivo al análisis de la realidad costarricense, de la producción jurisprudencial, sobre el tema por parte de nuestra Sala Constitucional, eso sí, con un límite temporal: los pronunciamientos de la década de los noventa.

\section{Precisiones conceptuales}

\subsection{Concepto de norma penal en blanco}

BINDING fue el autor que por primera vez (en 1872) propuso la expresión "ley penal en blanco" (traducción del término "Blanckettstrafgesetz"), para referirse a un peculiar grupo de normas penales que, aunque señalaban la sanción, su presupuesto se encontraba en violaciones a regulaciones de las autoridades administrativas. ${ }^{7}$

La estructura ordinaria de una norma penal contiene el supuesto de hecho y la consecuencia jurídica, esto es, la sanción. Se denomina norma penal en blanco, cuando una parte de esa estructura: el supuesto de hecho (para ser más precisa, una parte del mismo) no la contiene la propia ley, sino que se remite a otra norma distinta; son leyes necesitadas de complemento ${ }^{8}$.

\footnotetext{
5 Art. 39 Const. Pol.- "A nadie se hará sufrir pena sino por delito, cuasidelito o falta, sancionados por ley anterior $\mathrm{y}$ en virtud de sentencia firma dictada por autoridad competente, previa oportunidad concedida al indiciado para ejercitar su defensa y mediante la necesaria demostración de culpabilidad."

${ }^{6}$ SSC 1999-08984, de las 15:30 hrs. del 17 de noviembre de 1999: "Asimismo, también se ha señalado que, en virtud de este principio, es que se garantiza que ninguna acción humana puede constituir delito, aunque aparezca inmoral o contraria a los intereses colectivos, si no la define como tal una ley anterior a su ejecución, dictada por órgano competente."

7 LUZÓN PEÑA, Curso DP, PG, I, 1996, p.147; DOVAL PAIS, Norma penal, 1999, p. 95.

${ }^{8}$ Cfr. GARCIA ARÁN, EPC, XVI, 1992-1993, p.66; MORILLAS CUEVA/ RUIZ ANTÓN, MDP, 1992, p.66; RODAS MONSALVE, Protección penal, 1993, p.216; SILVA SÁNCHEZ, LL, 1993-1, p.967; LUZÓN PEÑA, Curso DP, PG, I, 1996, p. 147 (el autor hace una distinción en cuanto al supuesto de hecho en el sentido de que si una parte de él está regulado en otra norma extrapenal, la "norma penal no es estructuralmente incompleta en su contenido..." Pero "si en algún caso hay una remisión en bloque de la totalidad del supuesto de hecho típico a otra norma extrapenal, entonces, formalmente la ley penal en blanco hace una referencia al supuesto de hecho delictivo, realmente es una norma estructuralmente incompleta y que materialmente incumple la exigencia del principio de legalidad de que sea la propia ley penal la que fije con precisión las características del delito."); CONDE-PUMPIDO TOURÓN, CP, Vol. II, 1997, p.3230; MUÑOZ CONDE/GARCÍA ARÁN, DP, PG, 1998, p.114; TIEDEMANN, RCP, Vol.1, n²2, 1998, p.515; DOVAL PAIS, Norma penal, 1999, pp. 98 ss..
} 


\subsection{Rango de la norma complementadora}

En el seno de la teoría de las normas penales en blanco existen dos concepciones básicas (producto de las aportaciones de BINDING y de MEZGER): Una amplia que propone tres categorías para perfeccionar el tipo, en función de que el complemento se encuentre en: a) la misma ley penal; b) en otra ley, pero emanada de la misma instancia legislativa; y c) en otra norma dictada por instancia legislativa distinta. Sin embargo, parece imposible acogerla pues se llega a equiparar a las normas penales incompletas ${ }^{9}$, perdiendo además la virtud de dinamismo que es una de las características más atrayentes, pues siempre estarían sometidas al tedioso trámite legislativo.

Otra postura, la restrictiva mantiene que sólo son normas penales en blanco aquellas que no concretan el supuesto de hecho y cuya remisión se hace a disposiciones inferiores a la ley (reglamento, disposición en particular o acto administrativo de una autoridad); modalidad sobre la que se han formulado varias críticas en torno a su legitimidad constitucional. ${ }^{10}$

Por ello surge una tesis intermedia que sostiene son normas penales en blanco, aquellas cuyo supuesto de hecho se localiza en una remisión de la ley penal a leyes no penales (ley penal en blanco impropia) o a disposiciones de carácter inferior (ley penal en blanco propia). ${ }^{11}$

Es precisamente esta última modalidad la más acertada al momento de definir una norma penal en blanco, pues en esta alternativa tiene sentido la función práctica que se le asigna a la norma penal en blanco, no encasillando en rígidos preceptos penales algunas circunstancias necesarias (pero no esenciales) en el tipo, situaciones que frente a la actual sociedad (dado el avance

\footnotetext{
9 No obstante, este es el criterio seguido por la Sala Constitucional de Costa Rica, así lo ilustran la sentencia 187790, de las 16:02 hrs. del 19 de diciembre de 1990: “... 'leyes penales en blanco'; denominación bajo la que se analiza el problema causado por la no plenitud del tipo; sea cuando se necesita recurrir a otra norma de igual, superior o inferior rango, para lograr el tipo totalmente integrado." En igual sentido SSC No. 3465-93 de las 15 hrs. del 20 de julio de 1993; SSC No. 5060-94 de las 17:32 hrs. del 6 de setiembre de 1994.

${ }^{10}$ Cfr. GARCIA ARAN, EPC, XVI, 1992-1993, p.66 (acoge el concepto estricto); MORILLAS CUEVA/ RUIZ ANTÓN, MDP, 1992, p.65; RODAS MONSALVE, Protección penal, 1993, p.217; BACIGALUPO, AP, 1994-1, p.449; LUZÓN PEÑA, Curso DP, PG, I, 1996, p.148; TIEDEMANN, RCP, Vol.1, n², 1998, pp.516 - 517, que profundiza en algunas variantes; DOVAL PAIS, Norma penal, 1999, p.100: "En la concepción original de BINDING estas disposiciones de complemento se hallaban en las normas de rango inferior, emanadas -por delegación- de los Estados federados y de los municipios. MEZGER añadió otras dos posibilidades de complemento del 'blanco': la del complemento por la propia ley en otro lugar de su texto; y la del complemento por otra ley, emanada de la misma instancia legislativa. A aquellas a las que BINDING había limitado su referencia las denominó 'leyes penales en blanco en sentido estricto'; a estas otras dos modalidades, 'leyes penales en blanco en sentido amplio'."

${ }^{11}$ Seguidor de esta postura CASABÓ RUIZ, EPC, V, 1982, pp.253 - 254; MORILLAS CUEVA /RUIZ ANTÓN, MDP, 1992, p.65; LUZÓN PEÑA, Curso DP, PG, I, 1996, p.148, al referirse al concepto amplio de ley penal en blanco, alude a la denominada tesis intermedia, pues comprende no sólo a las normas de rango inferior, sino también a otras con rango de ley.
} 
informativo, tecnológico y demás), requieren una constante renovación. En todo caso, desde ya es vital aclarar que resulta inaceptable que el supuesto de hecho se traslade al contenido en la norma complementadora, pues ésta lo único que podrá albergar son datos no esenciales del núcleo de prohibición del tipo penal.

El recurso de la norma penal en blanco presenta dificultades intrinsecas en atención a su propia naturaleza, pero más aún si la autoridad que complementa el precepto no tiene competencia penal (como cuando interviene la Administración o los Municipios), todo lo cual origina diversas posturas que también pasare brevemente a abordar ${ }^{12}$. Luego se hará alusión a las garantías de legalidad que se deben considerar al momento de valorar si realmente es admisible el discurso de una norma penal en blanco, dentro de nuestro ejercicio profesional como vigilantes de derecho y la justicia.

\section{Posturas en torno al empleo de las normas penales en blanco}

\subsection{Argumentos en contra}

La remisión normativa de la norma penal en blanco sin duda ofrece mayor agilidad y flexibilidad en la adaptación del Derecho penal a los cambios de la realidad social. Pero existen quienes consideran, al analizar la norma penal en blanco, que la misma plantea innumerables problemas, entre los que destaco los siguientes: ${ }^{13}$

- El precepto no se agota en sí mismo, hay que remitirse a una normativa ajena.

- Con una dificultad añadida en algunos supuestos: lograr conocer con exactitud el cúmulo de disposiciones heterogéneas, de también muy diversa procedencia; por lo que conocer el perfil real de la infracción o conducta lesiva viola la seguridad jurídica que constitucionalmente ${ }^{14}$ se garantiza a los ciudadanos.

${ }^{12}$ BACIGALUPO, AP, 1994-1, p. 450; DE LA MATA BARRANCO, Homenaje a Casabó, Vol. I, 1997, p.587.

${ }^{13}$ Cfr. PERIS RIERA, Delitos, 1984, pp.45-47; BELTRÁN BALLESTER, PJ, IV, 1988, p.99; COLÁS TURÉGANO, PJ, nº.26, 1992, pp.224 - 225. Otros opositores de esta técnica BERDUGO GÓMEZ, en: TERRADILLOS BASOCO (Coord.), Delito ecológico, 1992, p.49; BERDUGO GÓMEZ/ARROYO ZAPATERO, MDP, PG, I, 1994, p.48: "Esta técnica, además de afectar al mandato de la reserva de ley en la definición de lo punible, por delegar en instancias administrativas parte de la tarea, puede afectar el mandato constitucional de determinación.” DEL CASTILLO FALCON, CPC, nº. 59, 1996, pp.512 ss.; BLANCO LOZANO, CPC, nº. 60, 1996, pp.712 ss.; Delito ecológico, 1997, pp.41-42, 72 ss; COBO DEL ROSAL, LL, 1996-3, p.1331, critica que el legislador en el Código Penal español de 1995 utiliza muchos elementos valorativos, señala: "se advierte la utilización por doquier de elementos subjetivos, cuando no de un uso excesivo de la denominada técnica de las leyes penales en blanco..."; aunque reconoce que de forma excepcional, es necesaria en la redacción de los preceptos. DOVAL PAIS, Norma penal, 1999, pp.129 ss., realiza un análisis detallado de todas las objeciones que se pueden hacer a esta técnica.

${ }^{14}$ Art. 39 Cons. Pol. Ver también por ejemplo art. 17.1 CE.- "Toda persona tiene derecho a la libertad y a la seguridad. Nadie puede ser privado de su libertad, sino con la observancia de lo establecido en este artículo y en los casos y en la forma previsto en la ley." 
- De ahí que se continúen suscitando dudas sobre el principio de legalidad ${ }^{15,16}$ y separación de poderes, base del moderno Estado de Derecho, pues evidentemente se palpa una delegación legislativa de consecuencias jurídicas (que por afectar esenciales derechos personales dentro de un Estado de Derecho), que usualmente exige en estos tópicos las máximas garantías.

- Mayor polémica surge cuando este debate se dirige a supuestos donde esa norma penal en blanco remite a otra de inferior rango, pues en tal evento -se ha manifestado- no sólo se quiebra el principio de legalidad, sino además el de reserva de ley. ${ }^{17}$

La jurisprudencia española puede ilustrar este temor con una Sentencia de la Audiencia Provincial de Barcelona de $1988 .{ }^{18}$ En este caso, mientras eran procesados los directivos de la Central Térmica Cercs, propiedad de FECSA, por vertidos contaminantes en cantidad que superaba la autorizada por reglamento, el Gobierno eleva la cuantía de vertidos autorizados. El asunto luego paso al conocimiento del Tribunal Supremo, que en sentencia del 30 de noviembre de 1990 resolvía que, aunque el imputado argumentaba que su conducta resultaba atípica, pues los niveles de contaminación gaseosa y sólida originariamente previstos en la normativa ambiental se habían elevado mediante resoluciones de la Dirección General de Industria integradas por Ordenes Ministeriales de fechas, 2 de agosto de 1985 y 24 de julio de 1985, dentro de parámetros que en ese momento no alcanzaban la cifra del reproche en su perjuicio, se debía desestimar su alegato, aduciendo que: a) Los Tribunales no pueden apartarse de las conclusiones contenidas en los dictámenes periciales, salvo cuando surjan razones objetivas que lo justifiquen. b) Por el principio de legalidad penal, en virtud del cual las Ordenes

\footnotetext{
${ }^{15}$ El principio de legalidad de los delitos y de las penas es uno de los límites más importantes al poder punitivo del Estado, advierte MORILLAS CUEVA/ RUIZ ANTÓN, MDP, 1992, pp.4, 9 que en su apego "ningún hecho puede ser estimado como delito sin que una ley anterior lo haya calificado como tal ("nullum crimen sine lege"); no podrá aplicarse ninguna pena que no haya sido previamente establecida por la ley ("nulla poena sine lege")... (Su) auténtica eficacia... viene determinada en la práctica por la técnica de elaboración empleada en la descripción de conductas prohibidas y en la fijación de las penas." Por su parte BERDUGO GÓMEZ/ARROYO ZAPATERO, MDP, PG, I, 1994, p.45 consideran que dentro de este principio, existen diversos postulados: "la reserva absoluta de Ley -monopolio del Parlamento- para definir las conductas constitutivas de delito y disponer la aplicación de penas, con exclusión de otras disposiciones legales de inferior rango y de la costumbre; la exigencia de determinación, certeza o taxatividad de las normas penales; la prohibición de la interpretación extensiva y de la analogía in malam partem; la irretroactividad de las normas penales desfavorables para el reo; la prohibición de castigar lo mismo más de una vez (ne bis in idem)."

${ }^{16}$ En Costa Rica consagrado en el art. 39 Const. Pol. En el caso español tanto la doctrina (DÍAZ PALOS, Jurisprudencia penal, 1991, pp.144 ss.; RODAS MONSALVE, Protección penal, 1993, p.220; BERDUGO GÓMEZ/ARROYO ZAPATERO, MDP, PG, I, 1994, p.45) como el TC consideran que el art. 25 CE proclama el principio de legalidad; el citado precepto dispone: "Nadie puede ser condenado o sancionado por acciones u omisiones que en el momento de producirse no constituyan delito, falta o infracción administrativa, según la legislación vigente en aquel momento."

${ }^{17}$ Cfr. BERDUGO GÓMEZ/ARROYO ZAPATERO, MDP, PG, I, 1994, p.48.
}

${ }^{18}$ Sentencia de la Audiencia Provincial de Barcelona de 20 de febrero de 1988. 
Ministeriales posteriores no pueden derogar ni las leyes ni los reglamentos vigentes al momento de ocurrir la conducta imputada (en este caso la Ley 38/1972 de 22 de diciembre, de Protección del Medio Ambiente y su Reglamento, de fecha 6 de febrero de 1975, Decreto 833/1975). Por lo cual incluso comenta, que los razonamientos del imputado pudieron dar pie a discutir el error de derecho, pero no un error de hecho, como pretendió. ${ }^{19}$

El principal aporte de la STS del 30 de noviembre de 1990 es la reafirmación del principio de legalidad penal, pero además avala la jerarquía normativa por la cual resulta inadmisible que una Orden Ministerial (aún cuando resulte en beneficio para el reo) sea complemento de un reglamento y mucho menos una ley. Esta resolución, además, pone en claro que aún cuando la Administración tramitara leyes o adoptara otras disposiciones reglamentarias en las que se autoricen inmisiones o vertidos peligrosos e inadmisibles (según normativa internacional aceptada y con rigor científico), se estaría violentando el art. 45 de la Constitución española sobre derecho al medio ambiente ${ }^{20}$, la norma en cuestión sería inconstitucional.

BACIGALUPO considera que sólo sería posible aceptar la remisión a disposiciones de inferiores, reglamentos e incluso, ordenanzas municipales, si no se afectan derechos fundamentales; si se diera su menoscabo, resulta indispensable una ley orgánica. ${ }^{21}$

\subsection{Argumentos a favor}

Desde quienes se declaran a favor de esta técnica, se defiende su uso no sólo en atención a razones prácticas dada la complejidad y el dinamismo que caracteriza ámbitos como el informático, ambiental, etc., además se entiende que en realidad las normas penales en blanco no resultan inconstitucionales. Esto ha llevado a un importante sector de la doctrina (no sólo costarricense sino también española y alemán, con sus matices), a subrayar su legalidad siempre que el legislador tome la "decisión incriminadora básica" y se describa en el tipo penal (aunque genéricamente) la conducta prohibida y sancionada, cediendo sólo a la Administración "la concretización de esta resolución". ${ }^{22}$ Otros más conservadores -entre los cuales me incluyo- prefieren una precisión más aguda del comportamiento

\footnotetext{
${ }^{19}$ STS del 30 de noviembre de 1990 (Ar. 9269).

${ }^{20} 1$. "Todos tienen el derecho a disfrutar de un medio ambiente adecuado para el desarrollo de la persona, así como el deber de conservarlo..."

${ }^{21}$ BACIGALUPO, AP, 1994-1, p. 451.

${ }^{22}$ TIEDEMANN, Lecciones, 1993, p.142: "El Tribunal constitucional federal alemán en el año 1988 ha declarado inconstitucional una disposición penal de la Ley de Telecomunicaciones porque esta disposición cedió totalmente a la Administración las condiciones para las concesiones de licencias para instalar radiofonía, condiciones que podían ser de cualquier clase al no estar establecidas por el legislador."
} 
prohibido, la existencia de razones técnicas precisas y la mención en el texto de ley de la puesta en peligro o lesión de un determinado bien jurídico, para evitar la tutela de una mera desobediencia del orden administrativo, salvaguardando también en lo posible el principio de legalidad y seguridad jurídica. ${ }^{23}$

Por otra parte, también se aclara que mucho del malestar con respecto a esta técnica obedece a su uso indiscriminado y sin debidas cautelas. Un ejemplo de ello lo encontramos en el art. 534 del anterior CP español que textualmente decía: "El que infringiere intencionalmente los derechos de propiedad industrial será castigado con las penas de arresto mayor y multa..."

\section{Garantías de legalidad}

Dentro del tema de la reserva de ley se distingue el carácter absoluto o relativo que pueda tener. Si existe reserva absoluta de ley, ningún acto de inferior rango puede tomarse por fuente; si es relativa, en cambio, la ley principal contiene datos básicos de la regulación que tienen la posibilidad de verse complementados con disposiciones cuyo rango es inferior. ${ }^{24}$

Pues bien, en materia penal se afirma el carácter absoluto de la reserva estatal, de manera que para resolver el conflicto nacido de su relación con las normas penales en blanco, dado que acepto como legítimo y necesario el reenvío advertida la complejidad y dinámica de fenómenos como el ambiental, incompatibles con las exigencias parlamentarias de reforma, es preciso que se cumplan determinados requisitos y sobre todo tener la claridad de que es un mecanismo excepcional..

El Tribunal Constitucional español se ha referido al tema. MESTRE DELGADO realiza un análisis de sus resoluciones en el tema y presenta algunas conclusiones generales 25 ; aunque realizando antes una aclaración en el sentido de que "las distintas Sentencias que han tenido por objeto remisiones normativas en materia sancionadora no han mantenido una línea argumental homogénea, pudiéndose afirmar, por el contrario, que en su resolución el Tribunal ha atendido más a la justicia del caso concreto que a la elaboración de una construcción general.’26 Pese a la disparidad en el contenido de las sentencias, a nivel doctrinal se extraen los siguientes resultados: 1) En materia penal existe una reserva absoluta de Ley; 2) El principio de legalidad de las infracciones es, sin embargo, compatible con

\footnotetext{
${ }^{23}$ Por ejemplo, CASABÓ RUIZ, EPC, V, 1982, p.260; TERRADILLOS BASOCO, en: TERRADILLOS BASOCO (Coord.), Delito ecológico, 1992, p.90; LUZÓN PEÑA, Curso DP, PG, I, 1996, pp.150 ss.; DE LA MATA BARRANCO, Homenaje a Casabó, Vol. I, 1997, p.570.

${ }^{24}$ CASABÓ RUIZ, EPC, V,1982, p. 255.

${ }^{25}$ MESTRE DELGADO, ADPCP, 1988, pp. $512-516$.

${ }^{26}$ MESTRE DELGADO, ADPCP, 1988, p.513.
} 
la colaboración reglamentaria; 3) Los elementos fundamentales de la tipificación deben estar en la Ley; 4) La Ley ha de fijar los límites del Reglamento, que ha de estar subordinado a aquélla; 5) La deslegalización de materias sujetas a reserva de Ley es contraria a la Constitución. ${ }^{27}$

El Tribunal Constitucional español en la Sentencia 3/1988 del 21 de enero, admite el uso de normas penales en blanco, acepta la "colaboración reglamentaria en la normativa sancionadora", pero exigiendo que "queden los suficientemente determinados los elementos esenciales de la conducta", sea que en respeto a la reserva de ley en materia penal, debe estar descrito el contenido de desvalor en cuanto a la lesión o puesta en peligro del bien jurídico tutelado. ${ }^{28}$ Con posterioridad ha precisado su postura y en Sentencia del 5 de julio de 1990 afirmó la constitucionalidad de los tipos penales en blanco. En aquella ocasión advirtió que era posible la incorporación al tipo de elementos normativos, como ya lo había reconocido la Sentencia 62/1982 del mismo Tribunal, que la utilización legislativa y consecuente aplicación judicial de la norma en blanco no planteaba problemas de inconstitucionalidad. La Sentencia del 5 de julio de 1990 destaca tres datos que asientan la legalidad de este tipo de normas ${ }^{29}$ :

La misma disposición debe disponer el reenvío, de manera que sea expreso y justificado, en tutela al bien jurídico protegido.

a) El tipo penal debe incluir no sólo la infracción, sino además el núcleo esencial del hecho ilícito ${ }^{30}$.

${ }^{27}$ MESTRE DELGADO, ADPCP, 1988, pp. 512 - 516. Luego DE LA MATA BARRANCO, Homenaje a Casabó, Vol. I, 1997, p.591 reitera las mismas conclusiones.

${ }^{28}$ Sobre el tema BLANCO LOZANO, El delito ecológico, 1997, p.45; MUÑOZ CONDE/ GARCÍAARÁN, DP, PG, 1998, p. 115

${ }^{29}$ STC del 5 de julio de 1990 (Ar.127). Comentarios respecto de esta sentencia GARCIA ARAN, EPC, XVI, 19921993, pp. 83 ss.; BERDUGO GÓMEZ/ARROYO ZAPATERO, MDP, PG, I, 1994, p.48; CONDE-PUMPIDO TOURÓN, LL, 1996-2 p.1552; CP, Vol. II, 1997, pp.3223, 3229; BLANCO LOZANO, Delito ecológico, 1997, pp. 44 ss.; MORALES PRATS, Homenaje a Casabó, Vol. II, 1997, p.482; MUÑOZ CONDE/ GARCÍA ARÁN, DP, PG, 1998, pp.115 - 116. Otra STC español que reitera esta postura es la del 25 de marzo de 1993 (Ar.111). El Tribunal Supremo español se ha referido expresamente a este tema, concluyendo en idénticos términos como lo acreditan las resoluciones del 3 de abril de $1995^{29}$ y la del 1 de febrero de 1997 (STS del 1 de febrero de 1997. Ar. 687).

${ }^{30}$ Destaca la crítica efectuada por GARCIA ARAN, EPC, XVI, 1992-1993, pp.88 ss. que cuestiona lo que el TC español considera "núcleo esencial de la prohibición", que califica como "artificiosa" pues todos los elementos típicos son esenciales para la definición del delito: "Si se parte de la base de que la infracción administrativa es uno de los elementos típicos y se considera que los restantes son 'suficientes' para configurar el núcleo esencial de la prohibición, es porque, en definitiva, se está admitiendo que existen elementos esenciales (los que configuran el núcleo) y elementos accidentales en la definición del hecho punible: la infracción administrativa sería pues un elemento accidental en la materia de prohibición. Entiendo, por el contrario, que la distinción 'elementos esenciales-elementos accidentales' no es aplicable en este caso. Cuando se utiliza -por ejemplo- en el... Código Penal- es para diferenciar aquellos que son imprescindibles para configurar el injusto, de los que suponen modulaciones agravatorias o atenuatorias del mismo. $\mathrm{Y}$ ahí radica precisamente el problema: en las remisiones en bloque que estamos analizando, tan imprescindible es la infracción administrativa como los restantes elementos típicos definidos por el legislador, para que podamos concluir la presencia del hecho típico, o lo que es lo mismo... sin infracción administrativa, no hay delito." 
b) Así se cumple la exigencia de certeza, pues la conducta ilícita se encuentra suficientemente determinada.

Sin embargo, siempre continúan nebulosas en torno a la seguridad que implica este recurso.

En definitiva, la incompletud del supuesto de hecho es una de los mayores problemas de la norma penal en blanco. ¿Por qué? Es difícil establecer la frontera entre lo que resulta esencial y lo que puede calificarse de complementario. La conducta prohibida en este tipo de leyes nunca es completa, existe una omisión o referencia no explícita sobre la acción u omisión prohibida. Esto presenta un problema de indeterminación que atañe no sólo al Juez (en su relación con la norma), sino que obviamente, afecta al conocimiento del ciudadano para conocer lo prohibido por el ordenamiento (vulnerando el principio de seguridad jurídica), nunca se podrá garantizar plenamente la predeterminación normativa de las conductas ilícitas, pues una de las razones funcionales de las normas penales en blanco es abarcar también todas las disposiciones que pudieran entrar en vigor, permitiendo la aparición imprevisible de nuevas conductas delictivas en sede penal. ${ }^{31}$

De ahí, que se estime imprescindible que cuando se aluda al "núcleo esencial de prohibición" se deba exigir que el mismo no sólo exista en la norma penal en blanco, siendo de esperar se detallen las características de la acción (verbigracia, si se exige o no un resultado), atendiendo a todos los elementos típicos (objetivos y subjetivos) que caractericen la conducta ilícita y que procuran zanjar con seguridad el límite entre el riesgo permitido y lo que jurídico-penalmente resulta desaprobado, con excepción de aquello que es preciso concretar técnicamente a través de las leyes y otras disposiciones de rango inferior. ${ }^{32} 33$ Leyes o disposiciones de rango inferior que en lo posible deberán dirigirse en concreto a la materia, en opinión de LUZÓN PEÑA "precisando que se trata de aquellas que tienen una determinada

${ }^{31}$ En este sentido también se ha pronunciado DOVAL PAIS, Norma penal, 1999, pp.129 ss., 165 ss.

${ }^{32}$ LUZÓN PEÑA, Curso DP, PG, I, 1996, p.152.

${ }^{33}$ Para ahondar más en la referida concreción, GARCIA ARAN , EPC, XVI, 1992-1993, pp.71 ss. realiza una distinción subrayando dos formas básicas de remisión (aunque limitadas a la materia reglamentaria desde su postura "Bindingniana" del concepto de norma penal en blanco), contrasta entre las remisiones en bloque y las interpretativas. La remisión en bloque es donde la infracción de la normativa administrativa es un elemento típico, porque "se sanciona penalmente la desobediencia a la norma administrativa", eventualmente un delito bajo esta modalidad no sólo sanciona el bien jurídico penalmente protegido, sino también la no observancia de la normativa de reenvío (laboral, administrativa, etc.). Si no hay infracción del ordenamiento de reenvío no hay delito, si la hipótesis prevista antes en esa regulación fuera suprimida, las conductas aunque atentatorias o lesionantes del bien jurídico, quedarían impunes. Las remisiones de este tipo son inconstitucionales. La remisión interpretativa es aquella donde "la normativa extrapenal es necesaria para interpretar o integrar un elemento típico.". Sigue esta postura DOVAL PAIS, Norma penal, 1999, p.167. 
finalidad" 34 , incluso "en atención a los principios de ultima ratio, proporcionalidad, etc., la ley se plantee si es adecuado o no restringir el elemento típico infracción legal o reglamentaria, limitándolo p. ej. a las infracciones intencionales, o a las más graves o de múltiples preceptos, etc." ${ }^{35}$

La necesidad del empleo de las normas penales en blanco, pese a las críticas que se puedan verter, es reconocida tanto en doctrina como en la jurisprudencia, pero su uso se debe concretar a casos determinados (siempre en apego a los requisitos señalados), solo cuando no halla "otro recurso técnico posible que la remisión a la correspondiente legislación y reglamentación administrativa para delimitar lo que en cada momento se considera jurídicamente prohibido, y a la inversa, el ámbito del riesgo permitido, con independencia de que además el tipo señale y precise con otros requisitos adicionales los supuestos de mayor gravedad dentro de lo antijurídico que dan lugar a lo penalmente prohibido a efectos de ese delito." 36

\section{En síntesis, las garantías de legalidad para el uso de una norma penal en blanco a mi criterio serán:}

a) Que la misma describa el núcleo central de prohibición con una máxima exigencia (detallando acción, si es preciso o no un resultado, si se trata de delitos de lesión o de peligro, en suma todos los elementos objetivos y subjetivos posibles).

b) Que contenga expresamente la sanción y que el reenvío mismo se justifique en razón de la tutela del bien jurídico protegido, dada la complejidad y dinamismo de la materia a tutelar.

c) Teniendo claro que se trata de un recurso de carácter excepcional, indispensable para delimitar el ámbito de lo permitido y de lo jurídicamente prohibido.

d) Que dentro de una adecuada regulación es necesario optar por una relativa dependencia del Derecho penal -por ejemplo- al Derecho administrativo, que no permita reprochar penalmente infracciones genéricas de la normativa administrativa, sólo ocuparse de aquellas que resulten dañosas o peligrosas en razón

\footnotetext{
${ }^{34}$ Considero que aunque idealmente sería deseable el cuestionamiento (vía principios de ultima ratio, proporcionalidad, etc.) de otros datos como los mencionados por LUZÓN PEÑA, se debe exigir por mínimo el relativo a la finalidad, teniendo por satisfecha la garantía de legalidad -en este concreto punto- si se da la referencia expresa a la misma, pues en ella se determina bastante la esencia de la acción tenida por típicamente antijurídica, y se aporta en seguridad sobre el bien jurídico tutelado.

${ }^{35}$ LUZÓN PEÑA, Curso DP, PG, I, 1996, p.153.

${ }^{36}$ LUZÓN PEÑA, Curso DP, PG, I, 1996, p.151. Sobre esta opinión advierte varias consecuencias, una de ellas se refiere a que la remisión a reglamentos debe ser estrictamente necesaria por razón de la materia, para precisar y delimitar lo prohibido (y permitido); no es suficiente la conveniencia, la mayor flexibilidad o la justificación del bien jurídico tutelado (ofrecida por el TC). Totalmente respetuosa de la posición de LUZÓN PEÑA, difiero parcialmente en el sentido de que la alusión del bien jurídico tutelado hecha por el TC se asocie a motivos de mera conveniencia, pues considero se origina precisamente -en aquel Alto Tribunal-, cuando estima la peculiaridad de la materia que hace indispensable el recurso a la norma penal en blanco.
} 
del bien jurídico protegido en lo penal: No es el "puro ilícito administrativo formal" el que interesa, aunque el mismo resulta indispensable 37 ; la finalidad de protección ha de dirigirse a bienes específicos tutelados por el ordenamiento penal. Por ello las leyes o disposiciones de inferior rango del reenvío, al consignarse en el texto de la norma penal en blanco deben precisar como mínimo su finalidad (aunque lo idóneo sería el determinar también otras circunstancias como la intencionalidad requerida, gravedad, etc.). Pero además, esas disposiciones de rango inferior o leyes no orgánicas -en respeto al principio de legalidad- tendrán por límite el núcleo de prohibición contenido en la norma penal en blanco, de manera que, por ejemplo, podrán detallar cualquier tecnicismo propio de la materia a regular (dada su complejidad y constante mutación) pero en caso de albergar conductas que no sean reconducibles a alguna de las que presenta el tipo penal, no podrían a efectos penales considerarse complementadoras del tipo penal (aunque tengan utilidad dentro de la disciplina en que se encuentran), porque ello representaría una ampliación sí del núcleo esencial de la prohibición, que vulneraría el marco de los derechos fundamentales reservado a la creación vía ley orgánica del Estado. ${ }^{38}$

\title{
2. Análisis de la postura de la Sala Constitucional costarricense ${ }^{39}$
}

\begin{abstract}
El interés de esta sección es revisar la actuación de la Sala Constitucional ${ }^{40}$ cuando se ha enfrentado el tema de las normas penales en blanco, precisamente por constituir el vigilante por excelencia del principio de legalidad en la comunidad costarricense.
\end{abstract}

La Sala Constitucional ha mantenido en sus planteamientos una aceptación de la norma penal en blanco, como técnica útil en la sociedad actual. Al conceptuarla es de cita reiterada el voto

${ }^{37}$ GONZÁLEZ GUITIAN, EPC, XIV, 1991, p.121.

${ }^{38}$ En este sentido BACIGALUPO, AP, 1994-1, p. 451; CARBONELL MATEU, DP, 1995, pp.188 ss.: Partiendo de que siempre será preferible una remisión a una disposición de rango inferior que "una valoración judicial sin ninguna pauta normativa"; asume la técnica de las normas penales en blanco como "indeseable" (pero sin poderse ignorar su necesidad en estos días); que cuando aludan a normas de rango inferior no pueden considerarse ilegales ni contrarias al principio de reserva de ley, si con ello restringen el ámbito de lo prohibido, o simplemente no afectan el núcleo esencial de la conducta.

${ }^{39}$ La Sala Tercera de la Corte Suprema costarricense también se ha referido al tema de las normas penales en blanco, baste señalar el voto 570-F-93 de las 9:40 hrs. del 22 de octubre de 1993, que en lo que interesa consigna: "Extremar la creación de tipos abiertos al punto de generalizar de tal modo que sea posible encuadrar cualquier conducta en la prohibición penal, sería violatorio del principio de legalidad; pero la enunciación general de la conducta prohibida dando la 'pautas o reglas' para que el juez individualice la conducta en cada caso concreto, no atenta contra el principio nullum crimen sine lege. (...) En igual sentido también le corresponde al Poder Ejecutivo complementar algunos aspectos del contenido del tipo penal (normas penales en blanco), cuando el propio legislador señala en la descripción típica la necesidad de remitirse a algunos parámetros, límites o criterios fijados por las autoridades administrativas... donde el Poder Ejecutivo complementa el contenido del tipo, por medio de su potestad constitucional de reglamentación." Lo anterior debido a que como también lo expresó en otra sentencia (SST N ${ }^{\circ}$. 511-F-93 de las 9:00 hrs. del 10 de setiembre de 1993): “... es imposible crear un sistema legislativo de carácter pleno o hermético, de tal forma que todos los términos estén definidos en la ley sin duda alguna...”.

${ }^{40}$ Analizo sentencias de 1990 en adelante. 
1876-90 de las 16 horas del 19 de diciembre de 1990, que advertía era la "denominación bajo la que se analiza el problema causado por la no plenitud del tipo; sea cuando se necesita recurrir a otras normas de igual, superior o inferior rango, para lograr el tipo totalmente integrado." 41

\subsection{Principales rasgos del criterio de la Sala Constitucional respecto de las normas penales en blanco}

La doctrina elaborada por la Sala Constitucional costarricense se puede afirmar, presenta las siguientes características:

\subsection{Reconoce una estructura básica de los tipos penales}

De forma reitera señala que los "tipos penales deben estar estructurados básicamente como una proposición condicional, que consta de un presupuesto (descripción de la conducta) y una consecuencia (pena), en la primera debe necesariamente indicarse, al menos, quién es el sujeto activo, pues en los delitos propios reúne determinada condiciones (sic) (carácter de nacional, de empleado público, etc.) y cuál es la acción constitutiva de la infracción (verbo activo), sin estos dos elementos básicos (existen otros accesorios que pueden o no estar presentes en la descripción típica del hecho) puede asegurarse que no existe tipo penal." ${ }^{42}$

\subsection{Reconoce la esencialidad del tipo penal, aunque admite puntuales ex- cepciones}

La Sala subraya que vía principio de tipicidad se exige que la conducta punible se delimite de forma precisa, se declara totalmente contraria a los tipos abiertos ${ }^{43}$, en uno de sus votos advierte:

"Para que una conducta sea constitutiva de delito no es suficiente que sea antijurídica -contraria a derecho-, es necesario que esté tipificada, sea que se encuentre plenamente descrita en una norma (...) para ello la exigencia de la ley previa, pero esta exigencia no resulta suficiente sin la tipicidad, pues una ley que dijera por ejemplo: 'será constitutiva de delito cualquier acción contraria a las buenas costumbres', ninguna garantía representa para la ciudadanía, aunque sea previa,

\footnotetext{
${ }^{41}$ Ya se advirtió que esta postura refleja la concepción amplia de norma penal en blanco de este alto Tribunal. En idéntico sentido SSC No N $^{\circ} 115-95$ de las 20:24 del 13 de setiembre de 1995; SSC No. 1999-08984 de las 15:30 hrs. del 17 de noviembre de 1999.

${ }^{42}$ SSC 1877-90 de las 16:02 hrs. del 19 de diciembre de 1990. Reiteran este argumento otras resoluciones, verbigracia, SSC Nº. 4443-94 de las 9 hrs. del 19 de agosto de 1994; SSC No. 1999-08984 de las 15:30 hrs. del 17 de noviembre de 1999.

${ }^{43}$ Sobre los tipos abiertos vid. SSC N ${ }^{\circ} .2757-93$ de las 14:45 hrs. del 15 de junio de 1993; SSC No. 0490-94 de las 16:15 hrs. del 25 de enero de 1994.
} 
en este caso será el criterio del juez el que venga a dar los verdaderos contornos a la conducta para estimarla o no constitutiva de delito, en cambio si el hecho delictivo se acuña en un tipo y además éste es cerrado, el destinatario de la norma podrá imponerse fácilmente de su contenido... La función de garantía de la ley penal exige que los tipos sean redactados con la mayor claridad posible, para que tanto su contenido como sus límites puedan deducirse del texto lo más exactamente posible." 44

Se reconoce la relevancia de la tipicidad, pero también se hacen ver la existencia de situaciones particulares donde se "flexibiliza" este principio:

"... puede concluirse en la existencia de una obligación legislativa, a efecto de que la tipicidad se constituya en verdadera garantía ciudadana, propia de un Estado democrático de derecho, de utilizar técnicas legislativas que permitan tipificar correctamente las conductas que pretende reprimir como delito, pues la eficacia absoluta del principio de reserva, que como ya se indicó se encuentra establecido en el artículo 39 de la Constitución, sólo se da en los casos en que se logra vincular la actividad del juez a la ley, y es claro que ello se encuentra a su vez enteramente relacionado con el mayor o menor grado de concreción y claridad que logre el legislador. La necesaria utilización del idioma y sus restricciones obliga a que en algunos casos no pueda lograrse el mismo nivel de precisión, no por ello puede estimarse que la descripción presente problemas constitucionales en relación con la tipicidad, es establecer el límite de generalización o concreción que exige el principio de legalidad, debe hacerse en cada caso particular." 45

\subsection{Acepta y reconoce el uso de las normas penales en blanco, incluso a los reglamentos como norma complementadora de las mismas.}

La Sala Constitucional acepta el recurso a la norma penal en blanco en el ordenamiento jurídico costarricense:

“... en nuestro marco constitucional existe reserva de ley, sea que en esa materia sólo está permitido el actuar de los Poderes Legislativo y Ejecutivo por medio de leyes formales, pero a su vez que la técnica legislativa ha aceptado como válida y necesaria la utilización de normas penales no completas, para fijar los tipos

${ }^{44}$ SSC 1877-90 de las 16:02 hrs. del 19 de diciembre de 1990, que declara inconstitucional el art. 105 de la derogada Ley de Tránsito número 5930 de 13 de setiembre de 1976. Vid. también SSC 5755-94 de las 14:57 hrs. del 4 de octubre de 1994, que declara inconstitucional el art. 64 de la Ley de Zona Marítimo Terrestre, número 6043 del 2 de marzo de 1977.

${ }^{45}$ SSC 1877-90 de las 16:02 hrs. del 19 de diciembre de 1990. Vid. también SSC No. 1999-08984 de las 15:30 del 17 de noviembre de 1999 . 
penales, las que logran su plena integración al relacionárselas con otras, aún de menor rango, dentro de éstas los reglamentos." 46

De forma más expresa:

“... Se ha indicado también, que la norma puede hacer alusión a conceptos amplios o con gran capacidad de absorción, de manera tal que mediante una valoración pueda concretarse y definirse el tipo penal, es decir, se determine el sujeto activo y la acción que se sanciona. Sin embargo, esta práctica puede presentar problema de comprensión de la norma, pero en ningún caso, tales conceptos pueden significar tal vaguedad que no pueda delimitarse el contenido a que se refiere, haciendo ilusorio el principio de tipicidad. No debe olvidarse que esta Sala se pronunció sobre la constitucionalidad de las normas que requieren de otra norma para su complemento, y que la doctrina denomina 'norma penal en blanco', admitiendo su conformidad con el orden constitucional..." 47

$\mathrm{Y}$ en concreto sobre los reglamentos se cuestiona y resuelve:

“... ¿ ¿resulta posible sin lesionar el principio de división de poderes, que los tipos penales sean completados, en sus elementos, por un reglamento? no podemos contentarnos con señalar que el artículo 140 inciso $3^{\circ}$. de la Constitución Política dispone como atribución del Presidente de la República y su respectivo Ministro, el reglamentar las leyes, pues lo que interesa es establecer sí por las exigencias propias de la materia penal, en cuanto al principio de reserva de ley, resulta constitucionalmente posible el completar las normas con un reglamento. (...) Es criterio de la Sala que esa técnica no se aparta del marco constitucional de división de Poderes..." 48

Pero cuáles han sido los criterios para la admisión de esta técnica por la Sala Constitucional? Y lo más importante, esos parámetros son realmente una defensa al principio de legalidad?

\footnotetext{
${ }^{46}$ SSC 1876-90 de las 16 hrs. del 19 de diciembre de 1990. Vid. también SSC No. 3465-93 de las 15 hrs. del 20 de julio de 1993; SSC No. 3540-93 de las 8:51 hrs. del 23 de julio de 1993; SSC $\mathrm{N}^{\circ}$. 3541-93 de las 8:54 hrs. del 23 de julio de 1993; SSC Nº 5060-94 de las 17:32 hrs. del 6 de setiembre de 1994 (“... la doctrina de leyes penales en blanco, denominación bajo la que se analiza el problema causado por la no plenitud del tipo; sea cuando se necesita recurrir a otra norma de igual, superior o inferior rango, para lograr el tipo totalmente integrado."); SSC No. 1999-08984 de las 15:30 del 17 de noviembre de 1999.

${ }^{47}$ SSC $\mathrm{N}^{\circ} .8984-99$ de las 15:30 hrs. del 17 de noviembre de 1999.

${ }^{48}$ En este caso concreto advierte la SSC 1876-90 de las 16 hrs. del 19 de diciembre de 1990: "Tanto el recurrente como la Procuraduría estiman que ello es posible, el primero señala: ‘... En sana técnica legislativa, la remisión a las disposiciones del Ministerio de Salud con referencia a sustancias que causen adicción o a drogas estupefacientes de empleo delicado, es correcta, pues no podría pretenderse que conforme aparecieren nuevas sustancias químicas que encuadraran bajo el marco general de narcodependencias, hubiera que modificarse la ley para incluir cada sustancia en una enumeración taxativa...' y la segunda asegura '... el complemento por vía reglamentaria al contenido de una disposición penal, es una práctica totalmente aceptada en la mejor doctrina jurídica’.
} 


\section{Criterios de admisión de la norma penal en blanco: garantías de legalidad}

No hay que olvidar que la tipicidad constituye el elemento del delito que garantiza el principio de legalidad (nullum crimen sine lege), de manera que entre las acciones antijurídicas más destacadas, resultan delictivas sólo las dispuestas en la norma penal. Y que incluso, mediante la determinación legal de los distintos componentes de una acción es loable diferenciar los delitos entre sí. ${ }^{49}$

En cuanto a la admisión de la norma penal en blanco, básicamente se encuentran dos tipos de razonamiento. La SSC 1877-90 de las 16:02 hrs. del 19 de diciembre de 1990 ilustra uno de ellos:

'La deficiente técnica legislativa utilizada al redactar el numeral en comentario es contraria al artículo 39 de la Constitución, pues la norma no permite establecer con claridad cuál es la conducta constitutiva de la infracción punible. La tipicidad exige, como quedó dicho, que las conductas delictivas sean acuñadas en tipos, estos a su vez tienen una estructura básica, con sujeto activo y verbo activo, estructura que puede lograrse con la relación de uno o varios articulos de ley o reglamento, pero es necesario que estépresente para que exista tipo. La utilización de términos genéricos como Las infracciones a lo dispuesto en esta ley...', al tipificar una conducta como constitutiva de delito, resulta, por su vaguedad, contraria a lo dispuesto en el artículo 39 de la Constitución y asi debe declararse." 50

La segunda argumentación, posterior y más completa, se refleja entre otras resoluciones, en la SSC No. 2757-93 de las 14:45 hrs. del 15 de junio de $1993^{51}$, que sobre el tema señala:

"La constitucionalidad de esta técnica legislativa es generalmente admitida, en tanto tenga límites que permitan impedir una completa arbitrariedad en manos de la autoridad administrativa, que es justamente lo que quiere evitar el principio de legalidad de los delitos. Para que la materia de prohibición pueda válidamente ser remitida a una disposición de rango inferior (ej. decretos ejecutivos) es necesario que la ley penal tenga autonomía y que la disposición de rango inferior sea dependiente o complementaria. Para ello es necesario que la materia prohibida aparezca por lo menos fijada en su núcleo esencial de manera que la disposición de rango inferior, a la que remite, se encargue de señalar condiciones, circunstancias, límites y otros aspectos claramente complementarios".

Incluso en cuanto a la remisión a reglamentos especifica se admite "siempre que el Ejecutivo se mantenga dentro del marco propio de sus atribuciones constitucionales y que la ley que remite establezca con suficiente claridad los presupues-

${ }^{49}$ Cfr. LUZÓN PEÑA, Curso de DP, PG, 1996, p.296.

${ }^{50}$ SSC 1877-90 de las 16:02 hrs. del 19 de diciembre de 1990. SSC $\mathrm{N}^{\circ}$. 8984-99 de las 15:30 hrs. del 17 de noviembre de 1999.

${ }^{51}$ En igual sentido SSC Nº. 0490-94 de las 16:15 hrs. del 25 de enero de 1994. 
tos de la punibilidad, así como la clase y extensión de la pena." ${ }^{52}$ (La negrita no es del original).

En el primero de los razonamientos transcritos, nuestra Sala Constitucional pese a subrayar el respeto al principio de tipicidad, admitía que el tipo como estructura básica constituida por un sujeto y verbo activo, podía formarse incluso por la relación de uno o varios artículos de ley o reglamento. En este sentido, tal razonamiento es una evidente violación al principio de legalidad, permitiendo que mediante reglamento otra autoridad -la ejecutiva- decida la conducta típica penal de resorte exclusivamente legislativo, por imperativo constitucional.

El segundo criterio expuesto, representa una visión más prudente y allegada al principio de legalidad, bajo esta tesis la Sala Constitucional admite el recurso de la norma penal en blanco pero con límites, se concretan así: a) Que la materia de prohibición se fije en su núcleo esencial. b) Que la norma a la que remite sea dependiente o complementaria, que se refiera solo a aspectos "claramente complementarios". c) Que la norma penal en blanco contenga la clase y la extensión de la pena.

No obstante, es posible ubicar resoluciones donde no han sido coherentes con estos lineamientos. En cuanto al primero de ellos, relativo a fijar el núcleo esencial de prohibición, ya antes se hizo referencia a la SSC 1877-90 de las 16:02 hrs. del 19 de diciembre de 1990, que abre la opción de una norma penal en blanco que determina la acción típica mediante la relación de varias normas.

En los que respecta al segundo de ellos, es obligado reproducir lo que manifestó la Sala al conocer una acción de inconstitucionalidad planteada en contra del art. 394 inc. 2) del CP, en la ya mencionada SSC 1876-90 de las dieciséis horas del 19 de diciembre de 1990. La Sala primero hace suyas algunas palabras de la Procuraduría que sobre las normas penales no completas señalaba '...el complemento por vía reglamentaria al contenido de una disposición penal, es una práctica totalmente aceptada en la mejor doctrina jurídica'; por lo que de seguido los Honorables Magistrados en su resolución argumentaban:

"Es criterio de la Sala que esa técnica no se aparta del marco constitucional de división de Poderes, siempre que el Ejecutivo se mantenga dentro del marco propio de sus atribuciones constitucionales y que la ley que remite establezca con suficiente claridad los presupuestos de la punibilidad, así como la clase y extensión de la pena. (...) Para cada caso debe ser analizado por separado, en lo que interesa a la presente acción, la atribución del Ejecutivo para dictar el reglamento que se estima inconstitucional por el

${ }^{52}$ SSC 1876-90 de las 16 hrs. del 19 de diciembre de 1990. 
accionante, le deviene, como lo señala la Procuraduría General de la República al contestar la audiencia que se le confirió, de la propia Ley de Licores, número 10 de siete de octubre de mil novecientos treinta y seis que en su artículo 22 dispone: 'En los establecimientos públicos de licores no se permitirán juegos (ni aún los autorizados por ley), ni espectáculo o diversiones. Se entenderá que el juego, espectáculo o diversión se encuentra en el mismo establecimiento, cuando estuviere en departamento que tenga comunicación con aquél' pues si lo confrontamos con el que el Ejecutivo se limitó a desarrollar los conceptos empleados por el legislador al emitir la Ley de Licores, función propia de funciones que resultan propias del Legislativo. Dice así el artículo 16 del Reglamento: 'No se permitirá en los establecimientos dedicados a la venta de licores ningún tipo de juegos, ni aún los autorizados por ley, ni espectáculos, juegos de dados, exhibición de películas pornográficas, etc. Los permisos para instalar aparatos como rocolas o similares son discrecionales de los gobernadores provinciales y sólo podrán concederse en las capitales de provincia y cabeceras de cantón en los días sábados y de las seis de la tarde a las diez de la noche y siempre que se observe el orden.- Estos permisos pueden revocarlos en cualquier momento el gobernador respectivo, cuando se observare que contribuyen a la alteración del orden y la tranquilidad públicos o que violaren las medidas dictadas por el Ministerio de Salud tendientes a evitar la contaminación atmosférica por medio de la emisión de sonidos. "La norma reglamentaria en comentario es constitucionalmente válida y en tal razón resulta legítima para completar una norma penal en blanco."

Existe en la sentencia mencionada un voto salvado del Magistrado Piza Escalante, que declara la inconstitucionalidad del art. 394 del CP, pues para completar el tipo se utiliza un reglamento "... lo que equivale a permitir que sea el reglamento el que fije las conductas punibles y esto viola la Constitución Politica en su artículo 37. Las garantías individuales no son meramente formales, sino que son todo materiales. La interposición contraria permitiría al legislador delegar funciones propias que le estén por la Constitución, en forma expresa o implícita pero inequicova (en cuanto al régimen de los derechos fundamentales), lo que excluye de la potestad reglamentaria del Poder Ejecutivo el núcleo de los derechos fundamentales, entre ellos, de manera muy especial, la libertad personal, y el patrimonio, que son los bienes directamente implicados en la justicia penal."

Es obvio, en todo caso, que el ejemplo anterior ilustra un argumento contradictorio, pues por un lado se afirma que la ley que remite debe establecer claramente los presupuestos de punibilidad y por otra, son los reglamentos los que en realidad los determinan. Es decir, vía reglamento no se están determinando aspectos 
secundario o complementarios del tipo, sino que en realidad se define el núcleo de prohibición, lo que a todas luces resulta en definitiva inconstitucional.

En lo que respecta al tipo de sanción y su extensión, resulta de cita necesaria el voto $\mathrm{N}^{\circ}$. 5060-94 de las 16:32 hrs. del 6 de setiembre de 1994, que al analizar la constitucionalidad del artículo 343 del Código Penal defiende que: “... es precisamente un tipo penal en blanco, en cuanto remite a otras normas para determinar la sanción a imponer. La norma si define sin embargo, en forma clara y precisa, cuál es la acción humana que se considera delictiva, al señalar 'al que diere o permitiere al funcionario público una dádiva o la ventaja indebida.' Contiene la norma las acciones entendidas y consideradas antijurídicas, pero en cuanto a su penalidad remite a las sanciones previstas en los artículos 338, 339, 340, 341 y 342 del Código Penal pues la conducta del sujeto activo está en relación directa con la atribuible al funcionario público a que refieren las señaladas normas. El legislador optó por separar la penalidad de cada acción típica para remitirla a los artículos que anteceden, normas del mismo rango y evitar así la repetición constante de las consecuencias jurídicas derivadas del incumplimiento de las disposiciones y prohibiciones de la ley." Con todo respeto, a mi criterio la norma en cuestión no determina en forma adecuada la conducta típica, pero en caso de que así lo fuera, más parecería encontrarnos frente a una norma incompleta, que una legítima norma penal en blanco.

Resulta oportuno tener presente que el tipo cumple varias funciones, la primera de ellas es de garantía, ya que, sólo serán delito las conductas antijurídicas seleccionadas y determinadas en la norma penal, en la ley. Tiene una tarea de motivación o determinación general en los ciudadanos, en el sentido de que una concreta conducta es prohibida y sancionada, procurando motivar para que todos se abstengan de cometerla. Finalmente, tiene una función definidora y delimitadora en unos tipos frente a otros, pues como se advirtió, al indicar cada uno sus elementos constitutivos, se contribuye a la labor sistemática y clasificadora de la materia. ${ }^{53}$

De este recuento de sentencias de la Sala Constitucional se puede concluir que:

- En algunos supuestos existe confusión entre las normas incompletas y las normas penales en blanco.

- No existe una línea definida en cuanto a las garantías de legalidad de una norma penal en blanco. En ocasiones se permite que el tipo penal se complemente sin límite alguno con varias artículos de leyes o disposiciones de carácter inferior; mientras que en otras se afirma que las normas de complemento sólo pueden referirse a aspectos secundarios.

${ }^{53}$ LUZÓN PEÑA, Curso de DP, PG, 1996, p.296. 
- Es más, las transcripciones hechas acreditan que aún cuando la Sala defiende algunos límites básicos, al momento de aplicarlos resulta en algunas ocasiones contradictoria.

En definitiva, no existe un criterio jurisprudencial consolidado en la Sala Constitucional sobre el tema de las normas penales en blanco. Sin embargo, los principios que informan un Estado democrático sobre la base del respeto a los derechos fundamentales, hacen impostergable una línea vigilante en defensa de la seguridad jurídica de los ciudadanos y por supuesto, de la legalidad.

Se debe exigir no sólo la descripción del núcleo central de prohibición, sino que lo sea con una máxima exigencia, que la norma penal debe contener la sanción y que el reenvío mismo se justifique en razón de la tutela del bien jurídico protegido, dada la complejidad y dinamismo de la materia a tutelar, como algo excepcional, indispensable para delimitar el ámbito de lo permitido y de lo jurídicamente prohibido. Que dentro de una adecuada regulación es necesario optar por una relativa dependencia del Derecho penal -por ejemplo- al Derecho administrativo, que no permita reprochar penalmente infracciones genéricas de la normativa administrativa, sólo ocuparse de aquellas que resulten dañosas o peligrosas en razón del bien jurídico protegido en lo penal. Que la finalidad de protección ha de dirigirse a bienes específicos tutelados por el ordenamiento penal. Por ello las leyes o disposiciones de inferior rango del reenvío, al consignarse en el texto de la norma penal en blanco deben precisar como mínimo su finalidad (aunque lo idóneo sería el determinar también otras circunstancias como la intencionalidad requerida, gravedad, etc.). Pero además, esas disposiciones de rango inferior o leyes no orgánicas - en respeto al principio de legalidad- tendrán por límite el núcleo de prohibición contenido en la norma penal en blanco, de manera que, por ejemplo, podrán detallar cualquier tecnicismo propio de la materia (dada su complejidad y constante mutación) pero en caso de albergar conductas que no sean reconducibles a alguna de las que presenta el tipo penal, no podrían a efectos penales considerarse complementadoras del tipo penal (aunque tengan utilidad dentro de la disciplina en que se encuentran), porque ello representaría una ampliación sí del núcleo esencial de la prohibición, que vulneraría el marco de los derechos fundamentales reservado a la creación vía ley orgánica del Estado.

La reacción a las debilidades del uso de las normas penales en blanco, ha dado paso a la propuesta de una nueva técnica legislativa dada -en criterio de algunos, la demostrada disfuncionalidad que estos tipos penales provocan en la tutela de bienes jurídicos. Así, MESTRE DELGADO, por ejemplo, sugiere dos vías alternativas: 1) Concretar en cada uno de estos tipos los elementos que constitu- 
yen la esencia del ilícito punible; o, 2) Superación de la naturaleza subsidiaria del Derecho penal: remisión al derecho administrativo sancionador. ${ }^{54}$ También un sector importante de la doctrina ${ }^{55}$ se muestra contrario al uso sólo de determinadas estructuras de remisión, como las denominadas remisiones en bloque. Otros en cambio, sólo aceptan el empleo de las normas penales en blanco cuando provoquen efectos "des-incriminadores", en respeto precisamente del principio de legalidad. ${ }^{56}$

Debe además tener presente el lector, que la profundización en la revisión interpretativa de las leyes penales en blanco no es tarea fácil, exenta de escollos. Deberá considerar que en un buen número de casos la propia legislación extrapenal no facilitará la función de selección cualitativa de los preceptos complementarios del tipo penal y, en otros casos, el propio reenvío a la normativa complementadora puede ser objeto de interpretaciones distorsionadoras de la estructura típica del delito en cuestión. Y que para desilusión de quienes defienden a los "padres de la patria" esta técnica de instrumentalización legislativa es producto en muchas veces, de la simple pereza o deseo de dejar en manos de la potestad reglamentaria determinados intereses, óptica desde la cual desapruebo en absoluto el uso de este recurso.

\section{BIBLIOGRAFÍA}

(Las palabras subrayadas son las que corresponden a la cita, tal y como figura dentro del contenido del trabajo).

- BACIGALUPO, Enrique, Sobre la problemática constitucional de las leyes penales en blanco, AP, 1994-1, pp.449 - 455. (cit. AP)

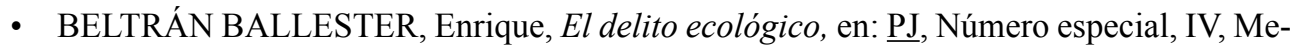
dio Ambiente, 1988, pp. 91 - 108.

- BERDUGO GÓMEZ DE LA TORRE, Ignacio, El medio ambiente como bien jurídico tutelado, en: TERRADILLOS BASOCO (Coord.), El delito ecológico, Editorial Trotta, Madrid, 1992, pp.41 - 50.

${ }_{54}^{54}$ MESTRE DELGAGO, ADPCP, 1988, pp.526 - 527.

${ }^{55}$ MESTRE DELGAGO, ADPCP, 1988, pp.517 ss.; GARCIA ARAN, EPC, XVI, 1992-1993, pp. 71 ss. Por su parte LUZÓN PEÑA, Curso DP, PG, I, 1996, pp.152 ss. advierte que su uso no es nunca estrictamente necesario o imprescindible.

${ }^{56}$ En este sentido se ha pronunciado BERDUGO GÓMEZ/ARROYO ZAPATERO, MDP, PG, I, 1994, p.48: "Nada obsta... a que cualquiera de las disposiciones legales...inferiores o distintas a la ley ordinaria y a la ley orgánica puedan y deban tener efectos indirectos des-incriminadores en las llamadas leyes penales en blanco, y no sólo porque la incriminación de una conducta requiera un juicio de antijuricidad, es decir, de contradicción de las mismas con todo el ordenamiento jurídico, sino porque el principio de legalidad es un principio garantizador de la libertad del ciudadano, y la restricción penal de la libertad no puede prevalecer sobre la libertad establecida por cualquier otra disposición legal." 
- BERDUGO GÓMEZ DE LA TORRE, Ignacio / ARROYO ZAPATERO, Luis, Manual de Derecho Penal, PG, I, Editorial Praxis, Barcelona, 1994 (cit. MDP).

- BLANCO LOZANO, Carlos, Acerca de algunas cuestiones básicas del derecho penal ambiental en el nuevo Código penal de 1995, en: CPC, n. . 60, 1996, pp.705 - 729.

- Artículos 325 y 328 del Código Penal: Problemas prácticos de aplicación, LL, 1997-4, pp. $1320-1332$.

- El delito ecológico. Manual operativo, Editorial Montecorvo, S.A., Madrid, 1997.

- CARBONELL MATEU, Juan Carlos, Derecho penal: Conceptos y principios constitucionales, Tirant lo blanch, Valencia, 1995 (cit. DP).

- CASABÓ RUIZ, José R., La capacidad normativa de las comunidades autónomas en la protección penal del medio ambiente, en: EPC, V, 1982, pp.235-260.

- COBO DEL ROSAL, Manuel, Consideración general sobre el nuevo Código penal, $\underline{\mathrm{LL}}$, 1996-3, pp.1331 - 1332.

- COLÁS TURÉGANO, María Asunción, Art.347 bis. ¿Ruptura con el principio de legalidad? en: $\underline{\text { PJ }}$, n. ${ }^{\circ} 26$, junio 1992, pp. 213 - 225.

- CONDE-PUMPIDO TOURÓN, Cándido, Comentarios a los artículos 325 y siguientes del CP, en: CONDE-PUMPIDO FERREIRO, Cándido (Direc.), Código Penal, Doctrina y jurisprudencia, Vol.II, Editorial trivium, Madrid, 1997, pp.3219 - 3269 (cit. CP).Vol. II, (cit. CP)

- DE LA MATA BARRANCO, Norberto, Configuración como ley penal en blanco de los delitos contra el ambiente, en: Estudios Jurídicos, Vol. I, Homenaje al Dr. José Ramón Casabó Ruiz, Valencia, 1997, pp.569-595 (cit. Homenaje a Casabó). Vol. I, (cit. Homenaje a Casabó)

- DEL CASTILlO FALCON CARO, María, El delito ecológico en la jurisprudencia criminal española, en: $\underline{\text { CPC }}$, n. ${ }^{\circ}$ 59, 1996, pp.511 - 526.

- DÍAZ PALOS, Fernando, La jurisprudencia penal ante la dogmática jurídica y la política criminal, Editorial COLEX, 1991.

- DOVAL PAIS, Antonio, Posibilidades y límites para la formulación de las normas penales. El caso de las leyes en blanco, Tirant lo Blanch, Valencia, 1999.

- GARCÍAARÁN, Mercedes, Remisiones normativas, leyes penales en blanco y estructura de la norma penal, en: EPC, XVI, 1992-1993, pp.63-103.

- HEINE, Günter, Accesoriedad administrativa en el Derecho Penal del Medio Ambiente, en: ADPCP, 1993, pp.289- 315.

- LUZÓN PEÑA, Diego-Manuel, Curso de Derecho Penal, PG, I, Editorial Universitas, S.A., Madrid, 1996 (Cit. $\underline{\text { Curso DP). }}$

- MATEOS RODRÍGUEZ-ARIAS, Antonio, Los delitos relativos a la protección del medio ambiente, Editorial COLEX, Madrid, 1998 (cit. Delitos del MAmb).

- MESTRE DELGADO, Esteban, “Límites constitucionales de las remisiones_normativas en materia penal” en: ADPCP, 1988, pp.503 - 527.

- MORALES PRATS, Fermín, La estructura del delito de contaminación ambiental. Dos cuestiones básicas: ley penal en blanco y concepto de peligro, en: Estudios Jurídicos, Vol. II, Homenaje Prof. Dr. José Ramón Casabó Ruiz, Universidad de Valencia, 1997, pp.475 - 499 (cit. Homenaje a Casabó). 
- MORILlAS CUEVA, Lorenzo y RUIZ ANTÓN, L. F., Manual de Derecho Penal, PG, I., Editorial Revista de Derecho Privado, 1992 (cit. MDP).

- MUÑOZ-CONDE, Francisco/ GARCÍA-ARÁN, Mercedes, Derecho penal, PG, $3^{\mathrm{a}}$ dición, Tirant lo blanch, Valencia, 1998 (cit. DP).

- PERIS RIERA, Jaime Miguel, Delitos contra el medio ambiente, Valencia, 1984.

- RODAS MONSALVE, Julio César, Protección penal y medio ambiente, $1^{\mathrm{a}}$ edición, PPU, Barcelona, 1993.

- SILVA SÁNCHEZ, Jesús María, ¿Competencia “indirecta” de las comunidades autónomas en materia de Derecho penal?, LL, 1993-1, pp.964-982.

- TERRADILLOS BASOCO, Juan, El ilícito ecológico: sanción penal - sanción administrativa, en: TERRADILLOS BASOCO (Coord.), El delito ecológico, Editorial Trotta, Madrid, 1992, pp.79- 105.

- TIEDEMANN, Klaus, La ley penal en blanco: concepto y cuestiones conexas, en: $\underline{\mathrm{RCP}}$, Vol. 1, n. ${ }^{\circ} 2$, 1998, pp.515 - 541. 